\title{
Clinical assessment of diaphragm strength by cervical magnetic stimulation of the phrenic
} nerves

Carl-Hugo Hamnegård, Simon D Wragg, Gary H Mills, Dimitris Kyroussis, Michael I
Polkey, Björn Bake, John Moxham, Malcolm Green
Sniff transdiaphragmatic pressure (sniffPDI) is a useful measure of diaphragm strength. ${ }^{34}$ However, the validity of sniff testing depends on the subject making a maximal effort and it is increasingly recognised that submaximal activation is common during volitional muscle testing. ${ }^{5}$ Submaximal efforts are most likely to occur in patients who are ill or breathless. Nonvolitional testing by PDI measurement during bilateral electrical stimulation of the phrenic nerves overcomes this problem and can be useful. However, it may prove impossible to locate the phrenic nerves in some patients and it is sometimes difficult to maintain adequate simultaneous stimulation of both nerves. Repeated measurements may therefore be required to be sure that stimulation has been maximal. The technique can be uncomfortable, and if subjects are not relaxed twitch transdiaphragmatic pressure (TwPDI) can be misleadingly increased by muscle potentiation. ${ }^{6}$

Since it is less painful, cervical magnetic stimulation overcomes some of these difficulties and TwPDI is reproducible in normal subjects. ${ }^{78}$ However, magnetic stimulation is different from electrical stimulation in that it activates some of the muscles that act on the upper thorax. ${ }^{8}$ It is not clear whether this is an important problem when assessing patients. However since, like normal inspiration, cervical magnetic stimulation causes stabilisation of the upper thorax preventing the indrawing of the upper chest wall, it could be argued that it is no less physiological than electrical stimulation.

The purpose of the present study was to evaluate the clinical usefulness of cervical magnetic stimulation of the phrenic nerves when assessing diaphragm weakness in patients.

\section{Methods}

SUBJECTS

Twenty three normal subjects (five women) aged 20-54 years and 66 patients of mean age 48 (range 20-75) years referred for routine assessment of respiratory muscle function were studied. The protocol was approved by the hospital ethics committee and all subjects gave their informed consent.

\section{PROCEDURES}

Oesophageal and gastric pressures were recorded from latex balloon catheters (PK Morgan Rainham, Kent, UK) positioned and tested in the standard manner. ${ }^{910}$ Pressures were 
Table 1 General and clinical characteristics of the patients and normal subjects

\begin{tabular}{|c|c|c|c|c|c|c|}
\hline \multirow[b]{2}{*}{ Diagnosis/sympton } & \multirow[b]{2}{*}{ Total } & \multicolumn{2}{|c|}{ Sex } & \multirow[b]{2}{*}{ Age (years) } & \multicolumn{2}{|l|}{ Height $(\mathrm{cm})$} \\
\hline & & $M$ & $F$ & & Male & Female \\
\hline Bilateral diaphragm paralysis & 3 & 2 & 1 & $55(42-72)$ & $174(172-177)$ & 163 \\
\hline Diaphragm and phrenic nerve injury & 4 & 4 & 0 & $39(22-53)$ & $176(170-181)$ & \\
\hline Dyspnoea of unknown origin & 16 & 12 & 4 & $50(23-72)$ & $171(157-191)$ & $168(158-175)$ \\
\hline Hemidiaphragm paralysis & 6 & 6 & 0 & $54(34-75)$ & $177(170-193)$ & \\
\hline Kyphoscoliosis & 3 & 1 & 2 & $45(43-46)$ & 165 & $151(147-156)$ \\
\hline Motor neurone disease & 3 & 2 & 1 & $47(21-72)$ & $171(168-173)$ & 165 \\
\hline Myopathy & 5 & 3 & 2 & $45(32-58)$ & $178(170-184)$ & $168(160-176)$ \\
\hline Neuralgic amyotrophy & 5 & 5 & 0 & $47(42-57)$ & $176(172-184)$ & \\
\hline Systemic lupus erythematosis & 4 & 0 & 4 & $41(37-43)$ & & $156(150-163)$ \\
\hline Miscellaneous & 17 & 12 & 5 & $49(23-68)$ & $181(173-193)$ & $160(152-175)$ \\
\hline Normal subjects & 23 & 18 & 5 & $33(20-54)$ & $179(172-196)$ & $168(161-173)$ \\
\hline
\end{tabular}

Values are mean (range).

measured by Validyne MP45-1 differential pressure transducers, range $\pm 150 \mathrm{~cm} \mathrm{H}_{2} \mathrm{O}$, and amplified by carrier amplifiers (Validyne Co, Northridge, California, USA). These were calibrated before each study with a Universal Pressure Meter (BIO-TEK Instruments Inc., USA) which was regularly tested for accuracy with a water manometer. ${ }^{11}$ All signals were passed into a 12-bit NB-MIO-16 analog-digital board and a Macintosh Centris 650 computer (Apple Computer Inc, Cupertino, California, USA) running LabVIEW software (National Instruments, Austin, Texas, USA). All signals were sampled at $100 \mathrm{~Hz}$. Transdiaphragmatic pressure (PDI) was obtained by digital subtraction of oesophageal from gastric pressure using PDI at resting end-expiration as the reference point.

Magnetic stimulation was performed using a Magstim 200 (HP) (Magstim Co. Ltd, Whitland, Dyfed, UK) with a circular $90 \mathrm{~mm}$ coil. $^{7812}$ To find the optimal site for magnetic stimulation of the phrenic nerve roots in both normal subjects and patients the neck was flexed and the coil was placed over the spinous process of $\mathrm{C7}$. The coil was then moved up and down the cervical spine in the midline until the maximum response was obtained at $80 \%$ power output. Having found and marked the optimal site for stimulation, the subjects rested for 20 minutes to avoid twitch potentiation. ${ }^{6}$ TwPDI was then measured at $100 \%$ Magstim output as the mean of five twitches performed at least 30 seconds apart.

In eight patients TwPDI was also measured following bilateral supramaximal electrical stimulation. The phrenic nerves were stimulated percutaneously at the posterior border of the sternomastoid muscle at the level of the cricoid cartilage. ${ }^{13}$ Two pairs of bipolar electrodes (Medelec Ltd, Old Woking, Surrey, UK) with saline soaked felt tips were connected to a constant voltage stimulator (Digitimer type 3072) and a gated pulse generator (Digitimer type 2521, Welwyn Garden City, Herts, UK) which produced square wave impulses of $100 \mathrm{~ms}$ duration. The stimulation intensity was increased until supramaximal stimulation, as judged by surface electromyography and PDI, was achieved.

In all subjects maximal sniffs were performed after the magnetic or electrical stimulation to avoid twitch potentiation. Subjects were allowed to sniff at will and were given visual feedback of sniffPDI on the computer monitor.
Usually 10 sniffs were obtained. SniffPDI was taken as the largest PDI. ${ }^{4}$

All sniffs and twitches were performed at relaxed functional residual capacity (FRC) as judged by oesophageal and transdiaphragmatic pressure traces immediately prior to the manoeuvre.

Since sniffs are a volitional test the largest sniff for each subject was accepted for analysis, whereas for twitches the mean of all acceptable twitches was used. Correlations between TwPDI and sniffPDI were sought using simple regression analysis. The lower limit of normal for both TwPDI and sniffPDI was defined as two standard deviations less than the mean observed in normal subjects.

\section{Results}

The general characteristics of all subjects and clinical diagnoses of the patients are given in table 1. Mean (SD) TwPDI following magnetic stimulation of the phrenic nerves was $31(6) \mathrm{cm}$ $\mathrm{H}_{2} \mathrm{O}$ (range 18-45) for the normal subjects and 18 (11) $\mathrm{cm} \mathrm{H}_{2} \mathrm{O}$ (range 0-37) for the patients. Mean (SD) sniffPdi was $132(22) \mathrm{cm} \mathrm{H}_{2} \mathrm{O}$ (range 95-160) for the normal subjects and 73 (38) $\mathrm{cm} \mathrm{H}_{2} \mathrm{O}$ (range 8-169) for the patients. The relationship between TwPDI and sniffPDI in normal subjects and patients is shown in fig $1(r=0.77)$.

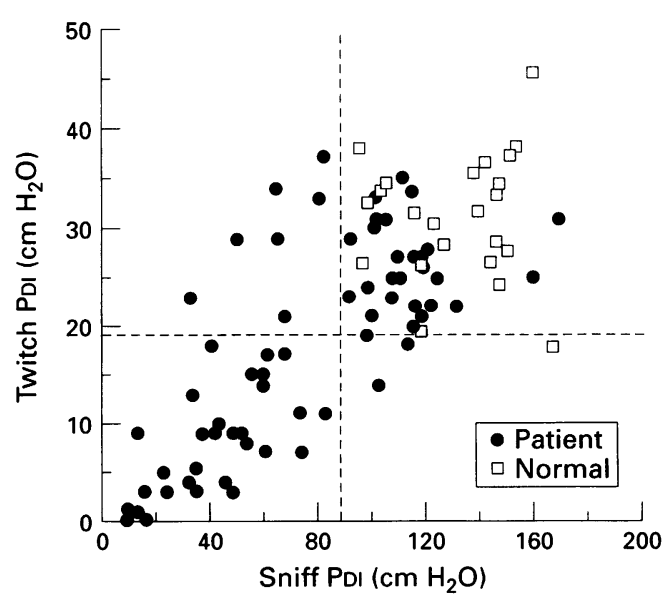

Figure 1 Relationship between transdiaphragmatic pressures obtained following magnetic stimulation of the phrenic nerves (twitch PDI) and during the sniff manoeuvre (sniff PDI) in 66 patients and 23 normal subjects $(r=0.77)$. The dashed lines indicate $-2 S D$ from the mean value of the normal subjects. 


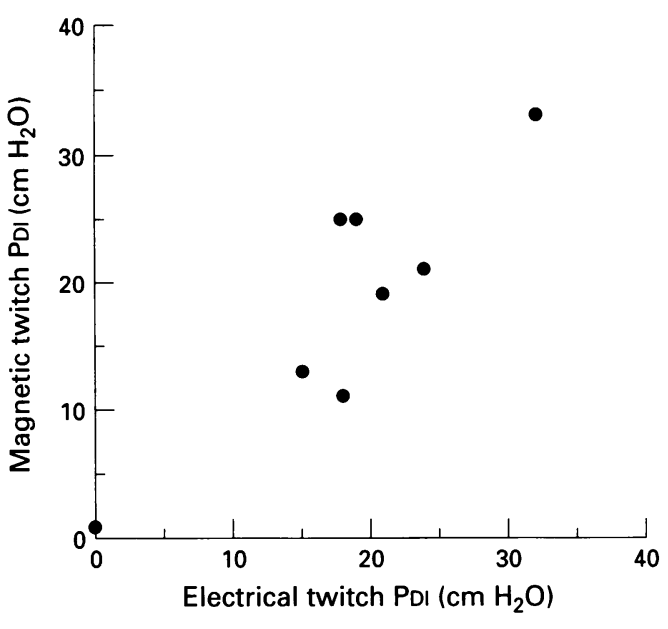

Figure 2 Comparison between magnetic and electrical twitch PDI in eight patients.

For purposes of comparison we took the lower limit of normal to be two standard deviations below the mean in the 23 normal subjects. This yielded values of $88 \mathrm{~cm} \mathrm{H}_{2} \mathrm{O}$ for sniffPDI and $19 \mathrm{~cm} \mathrm{H}_{2} \mathrm{O}$ for TwPDI. Using these criteria seven patients had a low sniffPDI but a normal TwPDI (this was $19 \%$ of those with a low sniffPDI and $11 \%$ of the total) whereas two patients had a low TwPDI and a normal sniffPDI ( $6 \%$ of those with a low TwPDI and $3 \%$ of the total).

Mean (SD) TwPDI following bilateral electrical stimulation of the phrenic nerves in eight patients was 18 (9) $\mathrm{cm} \mathrm{H}_{2} \mathrm{O}$ and following magnetic stimulation was 19 (10) $\mathrm{cm} \mathrm{H}_{2} \mathrm{O}$. The relationship between TwPDI following electrical stimulation and magnetic stimulation in these eight patients is shown in fig 2 .

\section{Discussion}

The main finding of the present study is that TwPDI produced by cervical magnetic stimulation is sufficiently practical to permit study of diaphragm strength in unselected patients with suspected respiratory muscle weakness. The results obtained closely correlated with established tests of diaphragm strength namely, the sniffPDI and PDI by electrical stimulation. Before enlarging on these findings some methodological issues will be addressed.

Twitch potentiation is a potential problem during assessment of diaphragm strength irrespective of the method of stimulation. ${ }^{6}{ }^{14}$ After a maximal voluntary contraction of the diaphragm the TwPDI at FRC can increase by $70 \% .^{6}$ To ensure that potentiation is avoided, subjects should rest, breathing quietly for 10-20 minutes before testing. ${ }^{6}$ This problem is harder to avoid with electrical stimulation because repeated stimulations are often required to find the optimum electrode position. Twitch potentiation may have misleadingly increased the TwPDI obtained in the eight patients submitted to electrical stimulation. This could explain why the TwPDI obtained with electrical stimulation was the same as that obtained with cervical magnetic stimulation, unlike trained normal subjects in which the
TwPDI obtained with cervical magnetic stimulation is usually slightly bigger. ${ }^{8}$

The effect of lung volume on TwPDI also needs to be considered. TwPDI changes by approximately $5 \mathrm{~cm} \mathrm{H}_{2} \mathrm{O}$ per litre acute change in lung volume ${ }^{15}$ and preliminary data suggest that patients with chronic hyperinflation also have a reduced TwPDI when assessed by cervical magnetic stimulation. ${ }^{16}$ Lung volume was not measured directly in the present study but all stimulations were undertaken at FRC as judged by the oesophageal and transdiaphragmatic pressure tracings during tidal breaths. Only TwPDI responses obtained at FRC were accepted for analysis. Clearly, if cervical magnetic stimulation were to be used for repeated measurements in the same patient, it would be important to ensure that the FRC was the same on each occasion.

A further potential drawback of magnetic stimulation is the activation of other muscles acting on the upper rib cage which may cause a somewhat higher magnetic than electrical TwPDI. ${ }^{8}$ In patients with bilateral diaphragm paralysis (as judged by sniffPDI and electrically stimulated TwPDI) cervical magnetic stimulation does not cause a negative oesophageal pressure, suggesting that the mechanism whereby magnetic stimulation produces a greater PDI is largely stiffening of the upper rib cage.${ }^{17}$ In practice, a good correlation was found between TwPDI and sniffPDI, suggesting that activation of the muscles of the upper thorax does not detract to any extent from the value of cervical magnetic stimulation in the clinical assessment of diaphragm strength.

In most patients, as expected, we observed a good correlation between cervical magnetic stimulation and sniffPDI. However, 19\% (seven of 37 patients) with reduced sniffPDI proved to have normal diaphragm strength when assessed by magnetic stimulation, suggesting that they may have made a submaximal effort during the sniff. Use of cervical magnetic stimulation in these patients enabled diaphragm weakness to be excluded, thus avoiding both anxiety and further investigation.

Equally, two patients (6\% of those with a low TwPDI) who had a mild weakness when judged by TwPDI had normal sniffPDI. This was possibly due to submaximal magnetic stimulation of the phrenic nerves. Submaximal stimulation can occur if the coil cannot be placed close enough to the phrenic nerves. One of the two patients had ankylosing spondylitis and could not flex her neck, preventing satisfactory contact of the magnetic coil. The second patient had systemic lupus erythematosus and had received high doses of steroids causing marked adiposity around the neck. In cushingoid patients we have previously observed that a "buffalo hump" can lead to submaximal phrenic nerve stimulation. ${ }^{18}$ However, it should be noted that electrical stimulation is also technically difficult if the neck is obese; indeed, the phrenic nerves may be impossible to locate.

In normal subjects supramaximal stimulation has been demonstrated ${ }^{78}$ but the plateau of the PDI response as the magnetic output increases occurs close to maximum stimulator output. 
Thus, in most normal subjects and patients supramaximal stimulation is only just achieved. Great care should therefore be taken to find the optimal position for the magnetic coil on the neck, and to flex the neck to obtain maximal contact. Failure to achieve this may result in stimulation that is significantly submaximal with consequently low TwPDI values. For these reasons we do not routinely measure diaphragm electromyographic changes. Instead we prefer simply to use the stimulator at $100 \%$ of maximum output and take care to optimise the position. This problem may be overcome in the future by the use of simultaneous bilateral/ unilateral phrenic nerve stimulation ${ }^{19}$ or a single cervical magnet with more power.

Our evaluation of cervical magnetic stimulation in clinical practice suggests that TwPDI invoked by this method is a valid measure of diaphragm strength which is acceptable to patients. The major advantage of magnetic stimulation is that the test is independent of patient aptitude and motivation. Because patients find it so acceptable it may be a useful technique for evaluating strategies aimed at altering muscle strength - for example, inspiratory muscle training.

In conclusion, magnetic stimulation of the phrenic nerves appears to be a clinically useful method for the detection of diaphragm weakness. It is a non-volitional and relatively easy test which has the potential to become a widely adopted method for the assessment of diaphragm strength.

Dr C-H Hamnegård was supported by a grant from the Swedish National Association for Heart and Lung Diseases and the University of Göteborg, Sweden

1 Agostoni E, Sant'Ambrogio G. The diaphragm. In Campbell EJM, Agostoni E, Newsom-Davis J, eds. The respiratory muscles: mechanics and neurological control. 2nd ed. London: Lloyd-Luke, 1970: 145-60.

2 Allen SM, Hunt B, Green M. Fall in vital capacity with posture. Br $\mathcal{f}$ Dis Chest 1985;79:267-71.

3 Mier-Jedrzejowicz A, Brophy C, Moxham J, Green M. Assessment of diaphragm weakness. Am Rev Respir Dis 1988;137:877-83.

4 Miller JM, Moxham J, Green M. The maximal sniff in the assessment of diaphragm function in man. Clin Sci 1985; 69:91-6.

5 Allen GM, Gandevia SC, McKenzie DK. Reliability of measurements of muscle strength and voluntary activation measurements of muscle strength and voluntary activation
using twitch interpolation. Muscle Nerve 1995;18:593-600.

6 Wragg S, Hamnegård C, Road J, Kyroussis D, Moran J, Green $M$, et al. Potentiation of diaphragmatic twitch after its voluntary activation. Thorax 1994;49:1234-7.

7 Similowski T, Fleury B, Launois S, Cathala HP, Bouche P, Derenne JP. Cervical magnetic stimulation: a new painless method for bilateral phrenic nerve stimulation in conscious humans. F Appl Physiol 1989;67:1311-8.

8 Wragg S, Aquilina R, Moran J, Ridding M, Hamnegård C$\mathrm{H}$, Green $\mathrm{M}$, et al. A comparison of cervical magnetic stimulation and bilateral percutaneous electrical stimulation of the phrenic nerves in normal subjects. Eur Respir f 1994;7:1788-92.

9 Milic-Emili J, Mead J, Turner JM, Glauser EM. Improved technique for estimating pleural pressure from esophageal technique for estimating pleural pressure
balloons. F Appl Physiol 1964;19:1101-6.

10 Baydur A, Pangiotis K, Behrakis K, Zin WA, Jaeger M, Milic-Emili JA. A simple method of assessing the validity of the esophageal balloon technique. Am Rev Respir Dis 1982;126:788-91.

11 Sixt R, Bake B. A simple pressure calibrator. Scand f Clin Lab Invest 1976;36:1-2.

12 Barker AT, Freeston IL, Jalinous R, Jaratt JA. Magnetic stimulation of the human brain and peripheral nervous system: an introduction and the results of an initial clinical evaluation. Neurosurgery 1987;20:100-9.

13 Newsom-Davis J. Phrenic nerve conduction in man. 7 Neurol Neurosurg Psychiatry 1967;30:420-6.

14 Mador MJ, Magalang UJ, Kufel TJ. Twitch potentiation following voluntary diaphragmatic contraction. $A m f R e$ following voluntary diaphragmatic cont
spir Crit Care Med 1994;149:739-43.

15 Hamnegård C-H, Wragg S, Mills G, Kyroussis D, Road J, Daskos G, et al. The effect of lung volume on transdiaphragmatic pressure. Eur Respir f 1995;8:1532-6.

16 Polkey MI, Kyroussis D, Hamnegård C- $\mathrm{H}$, Mills GH, Green $\mathrm{M}$, Moxham J. Diaphragm strength in chronic obstructive pulmonary disease. Am $\mathcal{F}$ Respir Crit Care Med 1996 (in press)

17 Mills G, Kyroussis D, Hamnegård C-H, Wragg S, Moxham $\mathrm{J}$, Green $M$. Chest wall activation during cervical magnetic phrenic stimulation (CMPS) does not produce inspiratory pressures. Am 7 Respir Crit Care Med 1995;151:A414.

18 Mills G, Jenkins PJ, Kyroussis D, Hamnegård C-H, Besser GM, Wass JAH, et al. Respiratory muscle strength in Cushing's syndrome. Eur Respir 7 1994;7:337s.

19 Mills GH, Kyroussis D, Hamnegård C-H, Wragg S, Moxham J, Green M. Unilateral magnetic stimulation of the phrenic nerve. Thorax 1995;50:1162-72. 